\section{OLIVE OIL IN OBSTRUCTION OF THE ESOPHAGUS.}

\author{
A. I. HODGDON, M.D. \\ PEARSON, MD.
}

A laborer consulted me one evening for an obstruct on of the csophagus due to the lodgment of a piece of food, probably meat, which he had swallowed at dinner. He had not been able to swallow anything, even water, since the obstruction occurred. I administered olive oil, a portion of which he was able to retain, and in about five minutes the obstruction was removed and he was able to swallow water readily.

\section{THE VAIUE OF ESERIN (PHYSOSTIGMIN) SALICYLATE IN OBSTRUCTION DUE TO INTESTINAL PARESIS. \\ CARL W. STROBELT, M.D. Attending Surgeon, Rutland Hospital. RUTLAND, VT.}

Nov. 16, 1907, I was called in consultation with Dr. I. to see an 8-year-old French girl presenting the following history:

History.-Six months previously she was attacked with colic pains in the right iliac region, followed by tenderness and mus. cular rigidity, obstinate constipation and slight rise of temperature. Efforts to move the bowels were successiul after three days. Recovery. During the past six months she had had three similar attacks, working out in much the same way.

Nov, 9, 1907, a fifth attack set in, beginning like the previous ones, the bowels, however, remaining obdurate, notwithstanding the employment of the same measures as in previous attacks. On the fourth day vomiting set in. On the fifth day, the ejected matters became stercoraceous, and continued so until this msultation, which was on the seventh day of the attack. Symptoms at this time were: Pulse 114, temperature 99.4, respiration 20 ; tongue clean and moist, eyes bright; pupils dilated; emaciation well marked; skin pale, dry and cool, and tensely drawn over the bones; abdomen tympanitic and hard, all muscles being contracted, especially so the recti, the linea alba and transversalis plainly marking its subdivisions; tenderness all over to pressure, especially so between umbilicus and the right anterior superior spinous process of the ilium; no marked dulness nor tumor-like masses, no flatness in flanks, nor tympany over liver.

Diagnosis.-Recurrent acute attack of chronic catarrhal appendicitis, and consequent reflex inhibition and reversal of normal peristalsis.

All efforts, though faithfully and skilfully conducted, for the relief of the constipation had signally failed. Considering the extremely Iow vitality and the possible disastrous effect of additional traumatic shock, it seemed highly desirable to tide the case over for interval operation.

Treatment.-I therefore advised the hypodermic injection of 1/50 gr. physostigmin salicylate and held myself in readiness to operate twelve hours later, if thi.s had no effect. One-half hour after the hypodermatic injection of this dose, the girl began to vomit great quantities of stercoraceous matter of very foul odor; the doctor said: "It seemed like two quarts." She was a very sick girl for about a half hour. She then had a slight dejection, consisting of a small amout of fecal matter, tegether with mucus, and "what seemed like pus." Two hours later there was a second action of the bowels with better results. The girl then dropped off to sleep and on awakening in the morning could take broths, etc., and was much improved. Operation was therefore postponed, pending return to a physical condition suitable for an interval operation.

Eserin has been found of great value to me in my abdominal work and I take the opportunity of presenting this clinical demonstration of its possibilities.
Craig, seeking to overcome intestinal paresis, has used eserin salicylate extensively for the past six years, with most encouraging results, which he has on several occasions published. I quote a significant paragraph from the latest of his articles:" "Tarious physiologists have proved that nothing so rapidly overcomes either a localized spasm or a localized area of paresis as an advancing peristaltic wave, and such waves eserin excites."

We thus get a glimpse of how eserin cloes its work. We must be sure, however, that the obstruction is due to intestinal paresis or disaster may come.

\section{VEROXAI DERMATITIS.}

\author{
PAUL G. WOOLLEY, M.D. \\ Chief Inspector of IIealth. \\ BANGKOK, SIAM.
}

The occasional notices of the bad effects of veronal, and more especially of the ability of that drug to give rise to cutaneous symptoms, encourages me to relate my own experiences with it.

Somewhat more than a year ago I felt the need of a mild soporific and purchased an original packet of veronal from a pharmacist in Singapore. At night, after dinner, I took about seven grains of the drug, and passed a very comfortable and restful night. The day after taking this dose I noticed a slightly tender, somewhat itchy, erythematous, macule over the first metacarpophalangeal joint of the left hand. The day following the lesion had become rather swollen and raised above the surrounding skin and was of a brilliant red color and felt tense and a little sore. A dav or two later the surface of this maculo-papule, which measured $2 \times 11 / 2 \mathrm{~cm}$., was covered with a number of small vesicles. Later still the vesicles dried and desquamation occurred, leaving a livid purple surface that turned to brown and then gradually faded to normal.

At this time it did not occur to me that the symptoms were due to the drug, but when, some months later, I took a second dose of perhaps 15 to 20 grains and observed the same lesion appear in the same place, I became suspicious and experimented with veronal, trional and sulphonal. I found that I could produce the lesion at will with veronal, but not with trional or sulplional. The only variation from the first experience occurred with doses above 15 grains, and then occasionally the lesions would appear symmetrically over both first metacarpophalangeal joints.

In the past eight months I have made the experiment at least four times with reronal and twice or three times with trional and once with sulphonal. I have noticed no other symptoms-no vertigo, stupor, no urinary changes-in fact, no change from the normal save in the respect I have noted above.

As regards the antecedent history of my case, let me say that I am not in the habit of using sedatives, hvpnotics or soporifics of any description, except when they seem to be especially called for, and that is very seldom - perhaps once in three months. When I have felt such a need I have used trional. My health is perfect and I have no other drug idiosyncrasies that I know about. It may be that the cases reported ${ }^{2}$ have simply been expressions of idiosyncrasies.

1. Post-Operative Obstructions, 'The Jocmat A. M. A., Oct. 12, 1007 .

2 Honse: The Jorkxal, 1907, xlviii, 1348, and Bulkley; Id. 1864 , and, yeihaps, other's. 